\section{O papel da Justiça nos planos e seguros de saúde no Brasil}

\author{
The role of the court system in regulating health \\ insurance plans in Brazil
}

\author{
${ }^{1}$ Escola Nacional de Saúde \\ Pública Sergio Arouca, \\ Fundação Oswaldo Cruz, Rio \\ de Janeiro, Brasil. \\ ${ }_{2}^{2}$ Laboratório de Economia \\ Política da Saúde, \\ Universidade Federal do \\ Rio de Janeiro, Rio de Janeiro, \\ Brasil. \\ Correspondência \\ L. Bahia \\ Laboratório de Economia \\ Política da Saúde, \\ Universidade Federal do Rio \\ de Janeiro. \\ Av. Pasteur 250, \\ Rio de Janeiro, $R J$ \\ 22290-240, Brasil. \\ ligiabahia@terra.com.br
}

\section{Abstract}

Consumer complaints against private health insurance plans and companies in Brazil have become increasingly frequent in the country's "supplementary" (non-public) health care sector, with numerous cases reaching the courts. The problem raised the need for regulation of this private market, which began in 1998, through Law no. 9.656. One of the challenges faced by the National Agency for Supplementary Health Care (ANS) is resistance to the legislation by health insurance companies, besides the fact that there are still some contracts not covered by this law. The objective of the current study was to analyze health insurance policyholders' appeals against court rulings for or against injunctions concerning coverage, in cases heard by the courts in Rio de Janeiro and São Paulo. The main data investigated were: court issuing the ruling; defendant; basis for the case; ruling by the Circuit Court and Court of Appeals; and the legal arguments. Based on the findings, the Brazilian court system still plays an important role in hearing and ruling on complaints by health insurance policyholders. The ANS has an important role in filling some gaps that have still not been solved in regulating the health insurance industry.

Prepaid Health Plans; Government Regulation; Judicial Power; Public Policies
Danielle Conte Alves 1

Ligia Bahia 2

André Feijó Barroso 2

\section{Introdução}

A Constituição Federal de 1988 representou um grande avanço no que tange ao reconhecimento da saúde como um direito fundamental dos brasileiros. Ao instituir o Sistema Único de Saúde (SUS) foram estabelecidos, entre outros princípios, a universalidade da cobertura e do atendimento, assim como a igualdade no acesso aos serviços de saúde.

O sistema de saúde brasileiro é formado por um mix público e privado, sendo composto por três subsetores: “1) o público, com serviços financiados e prestados pelo Estado, nos seus diversos níveis, incluindo-se os serviços próprios das forças armadas; 2) o privado (lucrativo e não-lucrativo), financiado por sistemas de reembolso, que podem ser recursos públicos e privados; 3) o de seguros privados, financiados diretamente pelo consumidor ou pelas empresas empregadoras (em geral de forma parcial), com diferentes níveis de preços e subsídios" 1 (p. 135).

A partir do final da década de 1980 e início dos anos 90, ocorreu o crescimento da demanda pela assistência suplementar, principalmente, devido à universalidade proposta pelo SUS, que levou à expansão da clientela do sistema público e à redução da oferta de serviços públicos de boa qualidade 2,3. Além disso, o crescente desfinanciamento da saúde pública tornou o segmento atraente aos investimentos de grupos econômicos privados 4 . Vale ressaltar, ainda, que o Estado 
brasileiro vem estimulando o setor suplementar através de renúncias fiscais na dedução do imposto de renda 5,6

O setor privado de saúde aparece representado no imaginário social como referência assistencial de melhor qualidade frente aos riscos e imprevistos dos agravos à saúde. Estratégias de marketing veiculadas pela mídia enfatizam a rapidez e a resolutividade desse mercado, demonstrando facilidade e comodidade no acesso aos serviços e aos mais modernos equipamentos diagnósticos e terapêuticos. Em contrapartida, grande quantidade de ações tramita na Justiça pleiteando reparação de danos causados pela má qualidade ou pela ausência de atendimento aos usuários da assistência privada à saúde 2 .

As reclamações dos consumidores devido às exclusões de coberturas, aumentos abusivos, longos períodos de carência, rescisões unilaterais de contrato e limitações de internações tornaram-se freqüentes no setor suplementar, com reflexos sobre o Poder Judiciário. Antes de 1998, na ausência de legislação específica, a norma mais freqüentemente utilizada para tentar dirimir os conflitos nas relações entre usuários e operadoras era o Código de Defesa do Consumidor (CDC). Com isso, ocorreu um aumento da pressão exercida sobre o Estado por parte dos usuários dos planos de saúde e das associações de defesa dos consumidores, para que fosse exercida uma efetiva fiscalização sobre esse mercado.

A problemática em questão foi colocada na agenda governamental e fez surgir a necessidade do estabelecimento de um ordenamento jurídico legal para o setor, o que levou à regulação desse mercado privado e à definição das suas responsabilidades. Essa regulação iniciou-se em 1998, com a promulgação da Lei $n^{\circ} .9 .656 / 987$ e aprofundou-se com a Lei $n^{o} .9 .661 / 2000$, a qual criou a Agência Nacional de Saúde Suplementar (ANS).

A Lei $n^{\circ}$. 9.656/98 busca regulamentar a oferta de serviços na relação de mercado entre operadoras e consumidores. Alguns dos temas considerados como objetos da regulamentação pela referida lei foram: ampliação de cobertura assistencial, o ressarcimento do SUS, o registro das operadoras e o acompanhamento de preços pelo governo 7. Segundo Bahia 9, o debate em torno da elaboração da Lei $n^{\circ}$. 9.656/98 revelou os abusos das operadoras contra os clientes e remeteu à esfera pública as atribuições de regulação e controle da assistência prestada pelas empresas de assistência médica suplementar. Contudo, não elaborou proposições efetivas para a regulação das extensas interfaces público-privadas da gestão dos riscos à saúde.
Após a publicação da lei em questão, os contratos de planos e seguros de saúde passaram a ser classificados em contratos antigos (anteriores a janeiro de 1999 - quando a lei entrou em vigor) e contratos novos (firmados já sob a vigência da nova legislação). Isso pelo fato de que a Lei $n^{o}$. 9.656/98, no artigo 35-E, estabelecia que algumas de suas determinações deveriam ser também obedecidas pelos contratos antigos. Contudo, o Supremo Tribunal Federal, em 21 de agosto de 2003, julgando pedido liminar da Adin 1931, proposta pela Confederação Nacional de Saúde - Hospitais, Estabelecimentos e Serviços (CNS), considerou o artigo 35-E inconstitucional, declarando que os contratos de planos de saúde celebrados antes da edição da Lei $n^{\circ}$. 9.656/98 não podem ser atingidos pela regulamentação específica dos planos de saúde. Dessa forma, os contratos antigos são regidos, principalmente, pelo CDC, enquanto que aos contratos novos é aplicada a legislação específica do setor. Vale ressaltar que a lei previamente citada prevê a aplicação subsidiária do CDC aos contratos de assistência privada à saúde.

A ANS foi criada por meio da Medida Provisória $n^{o}$. 1.928/99, convertida na Lei $n^{o}$. 9.961/2000. É uma autarquia vinculada ao Ministério da Saúde, que tem como características: autonomia política, administrativa e financeira, expressas por uma arrecadação própria; decisões em Diretoria Colegiada, cujos membros têm mandatos definidos em lei e não coincidentes; e o poder legal dado às agências reguladoras para a efetivação de suas resoluções. Sua finalidade é promover a defesa do interesse público na assistência suplementar à saúde, regular as operadoras setoriais - inclusive quanto às suas relações com prestadores e consumidores - e contribuir para o desenvolvimento das ações de saúde no país 10 .

De acordo com Almeida 11, a regulação pública do seguro privado em saúde tem três objetivos: a manutenção da estabilidade do mercado segurador, o controle da assimetria de informação e a maximização da participação do consumidor no mercado privado da saúde. Essas diferentes dimensões da regulação apontam para a proteção do consumidor e para níveis aceitáveis socialmente de justiça social.

No que concerne à maximização da participação do consumidor, as regulações têm tentado conciliar as práticas do mercado privado de seguros com as demandas sociais de justiça e maior eqüidade no acesso aos serviços de saúde e incluem normatizações de três tipos: proibição ou restrição de exclusões, proibição ou restrição da vinculação dos preços às condições de saúde, idade, sexo etc.; e obrigatoriedade de cobertura para determinados serviços ou benefícios 12 . 
Embora a regulação dos planos privados de saúde no Brasil tenha representado um grande avanço, resultado da mobilização da sociedade civil, dos esforços governamentais e do trabalho do Poder Legislativo, a atuação do Estado no setor ainda é restrita, pois a complexidade do sistema de saúde brasileiro exige a formulação de diretrizes condizentes com a concepção de que a saúde é um bem de relevância pública 12 .

Um dos desafios que a ANS enfrenta é a resistência das operadoras de planos de saúde perante a legislação, além do fato de ainda existirem planos não regidos pela lei que regulamenta o setor. Essa reação tem ocasionado várias divergências entre operadoras e a ANS, gerando, conseqüentemente, conflitos judiciais. Dessa forma, um dos meios disponíveis para que o consumidor de planos de saúde obtenha um direito perante a Justiça é o pedido de tutela antecipada.

$\mathrm{O}$ instituto da tutela antecipada apareceu por meio do novo artigo 273 do Código de Processo Civil (CPC) 13, alterado pela Lei no ${ }^{\circ}$. 8.952, de 13 de dezembro de 1994 14, de acordo com o descrito:

“Art. 273. O juiz poderá, a requerimento da parte, antecipar, total ou parcialmente, os efeitos da tutela pretendida no pedido inicial, desde que, existindo prova inequívoca, se convença da verossimilhança da alegação e:

I - haja fundado receio de dano irreparável ou de difícil reparação; ou

II - fique caracterizado o abuso de direito de defesa ou manifesto propósito protelatório do réu".

Em linhas gerais, são dois os requisitos necessários para a concessão da tutela antecipada. Em primeiro lugar, o juiz precisa se convencer da verossimilhança das alegações ou do relevante fundamento da demanda, ou seja, o autor precisa demonstrar que o pedido encontra suporte fático e que a realidade descrita encontra abrigo na legislação em vigor. $\mathrm{O}$ segundo requisito diz respeito ao perigo de dano irreparável ou de difícil reparação. $\mathrm{O}$ autor deve demonstrar que a demora no julgamento do mérito poderá provocar-lhe dano irreparável ou de difícil reparação, como, por exemplo, o agravar seu estado de saúde, ou mesmo, colocar sua vida em risco. Dessa forma, o instituto da tutela antecipada permite que o juiz propicie que a parte interessada usufrua, de imediato, dos efeitos pretendidos através do pedido formulado, assim como ocorreria na sentença final caso a decisão fosse favorável 15 .

Tendo em vista a escassa produção de conhecimentos que versam sobre as ações judiciais e os planos de saúde, torna-se de suma relevância ensejar a discussão a respeito dos problemas enfrentados pelos consumidores e do papel do Poder Judiciário frente a essa questão, a fim de fornecer subsídios para a construção de políticas públicas que logrem avanços no processo de regulação.

Nesse sentido, o objetivo do presente estudo foi analisar recursos de decisões judiciais, sobre pedidos de tutela antecipada, relacionados aos planos e seguros privados de saúde, julgados nos Tribunais de Justiça dos Estados do Rio de Janeiro e de São Paulo e comparar dois períodos de análise.

\section{Metodologia}

Foram analisadas as decisões proferidas pelos órgãos colegiados do Tribunal de Justiça do Rio de Janeiro e de São Paulo sobre pedidos de tutela antecipada formulados em ações movidas por beneficiários de planos e seguros de saúde. Dessa forma, estudou-se o agravo de instrumento, ou seja, o recurso da decisão de la Instância que concede ou não o pedido liminar da antecipação da tutela solicitado pelo consumidor de plano ou seguro de saúde.

Essa abordagem permite verificar o posicionamento da 1a Instância e confrontar com o da 2a Instância no que se refere ao maior ou menor índice de atendimento aos pedidos dos beneficiários do setor. Contudo, o trabalho não abrangeu as decisões de 1a Instância que não sofreram recurso para o Tribunal de Justiça.

As ações judiciais provenientes de São Paulo e Rio de Janeiro foram selecionadas para o estudo pelo fato de a cobertura de planos de saúde nesses estados abranger mais de $30 \%$ da população, sendo os estados que apresentam maiores percentuais da população coberta por planos de saúde 16 .

Foram comparados os períodos: de janeiro de 2003 a setembro de 2004 e o de setembro de 2004 (acórdãos não analisados no momento anterior) a agosto de 2005. A comparação entre os dois períodos estudados viabiliza a observação de possíveis diferenças no que concerne à posição do Poder Judiciário frente à problemática dos usuários de planos e seguros de saúde, assim como aos temas que motivaram as ações judiciais.

As decisões foram coletadas nas páginas da Internet dos Tribunais de Justiça de ambos os estados, por meio do sistema de busca do setor de jurisprudência, considerando o Agravo de Instrumento como tipo de Recurso. Foram feitas pesquisas utilizando as expressões "planos $e$ saúde e tutela e antecipada" e "seguros e saúde e tutela e antecipada".

Para fins de análise das decisões proferidas, foi utilizado um formulário (Figura 1) contendo os principais dados a serem pesquisados, o qual 
Formulário para análise de acórdãos.

\begin{tabular}{|c|c|}
\hline Acórdão $N^{\circ}$. (TJ/__ ) & \\
\hline Data do julgamento & $-1 / 200 \_$ \\
\hline Titularidade & $\begin{array}{l}\square \text { individual } \\
\square \text { coletiva: } \quad \square \text { ONG } \square \text { MP } \quad \square \text { Procon } \quad \square\end{array}$ \\
\hline Réu & \\
\hline Tema & 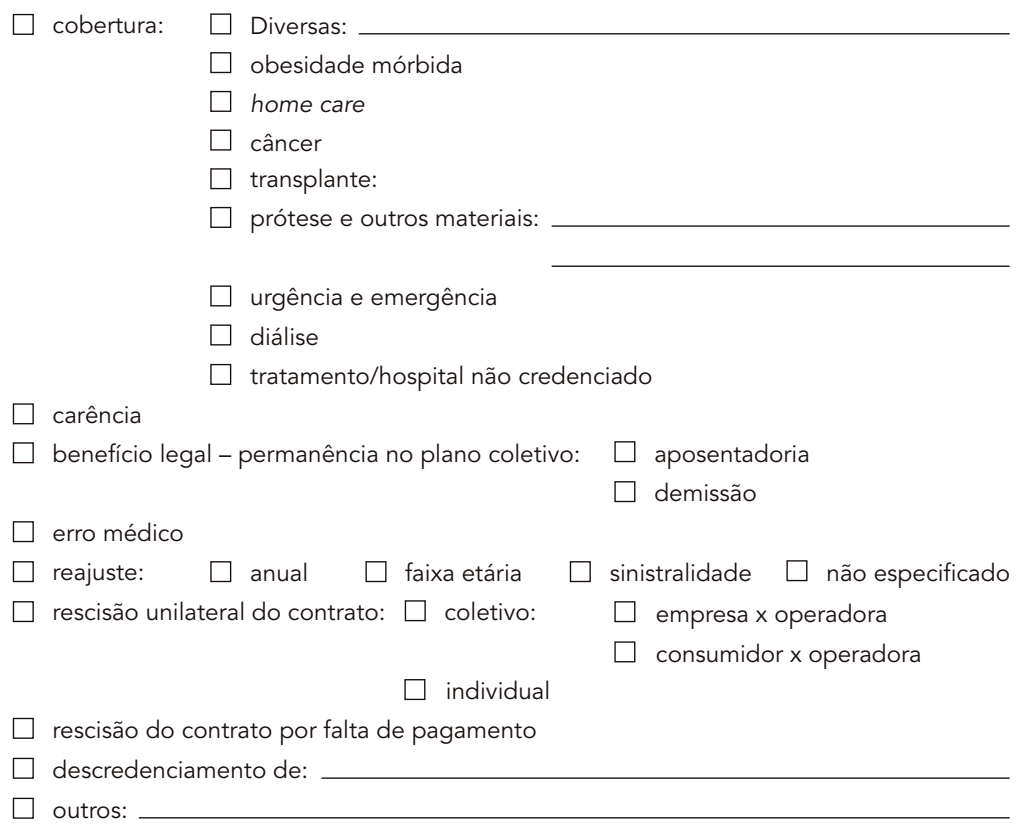 \\
\hline 1a Instância & $\begin{array}{l}\square \text { concedida } \quad \square \text { concedida percialmente } \quad \square \text { negada } \\
\square \text { outros (recurso prejudicado, acordo, postergada a análise) }\end{array}$ \\
\hline 2ª Instância & $\begin{array}{l}\square \text { concedida percialmente } \quad \square \text { mantida } \\
\square \text { cassada parcialmente } \quad \square \text { mantida nagativa }\end{array}$ \\
\hline Fundamentação & $\square$ L. 9.656/98 $\square$ CF $\square$ CPC \\
\hline Argumentação & \\
\hline
\end{tabular}

foi preenchido para cada uma das decisões. O formulário aborda os seguintes itens: Tribunal que proferiu a decisão; data de julgamento; número do agravo de instrumento; titularidade da ação; réu; tema debatido; posicionamento de 1a Instância; posicionamento de 2a Instância; fundamentação jurídica e trechos da argumentação utilizada. Merecem destaque os seguintes itens descritos.

\section{Titularidade}

Esse item permite identificar as ações individuais e as coletivas. Foram considerados de titularida- de coletiva apenas os casos de ações propostas por um dos entes legitimados pelo artigo 82 do CDC 17, ou seja, os casos de autores das chamadas ações coletivas.

\section{Réu}

Destacou-se o réu da ação principal, o que permitiu identificar as operadoras que motivaram um maior número de processos.

\section{Temas debatidos}

Os temas avaliados nas decisões foram: 
- Cobertura: diversa, obesidade mórbida, home care, câncer, transplante, próteses e outros materiais, urgência e emergência, diálise e tratamento/hospital não credenciado;

- Carência;

- Benefício legal: permanência no plano coletivo - aposentadoria e demissão [esse item diz respeito às decisões que versam sobre o direito dos aposentados e demitidos, sem justa causa, a permanecerem, por certo período de tempo, no plano coletivo da empresa onde trabalhavam, arcando com o valor integral da mensalidade];

- Erro médico;

- Reajustes: anuais, por mudança de faixa etária, sinistralidade, não especificado;

- Rescisão unilateral do contrato: coletivo (empresa $v s$. operadora e consumidor $v s$. operadora) ou individual. [Quanto aos contratos coletivos, o levantamento do número de decisões englobou as ações movidas pelas empresas, sindicatos ou associações contratantes dos planos de saúde e aquelas movidas por pessoas físicas (empregados, sindicalizados ou associados) contra as operadoras. Os casos de rescisão de contrato individual ou familiar abordam situações como falecimento do titular e alegação de fraude do consumidor, entre outros];

- Rescisão do contrato por falta de pagamento;

- Descredenciamento;

- Outros temas.

\section{Posicionamento da Justiça}

Foram especificados todos os possíveis resultados da 1a e 2ạ Instâncias. Primeira Instância: decisões que concedem, concedem parcialmente ou negam a tutela. Segunda Instância: decisões que concedem, concedem parcialmente, mantêm, cassam, cassam parcialmente a tutela anteriormente deferida ou mantêm a negativa anterior. As decisões consideradas favoráveis ao consumidor são as que concedem, concedem parcialmente ou mantêm a tutela concedida.

\section{Fundamentação}

O objetivo da coleta de dados a respeito da fundamentação é mensurar a utilização do CDC e da Lei $n^{o}$. 9.656/98, principais dispositivos legais pertinentes ao tema, nas decisões da Justiça. Além disso, foram consideradas as decisões que basearam no CPC e aquelas cujo fundamento não foi especificado. As decisões sobre os pedidos de antecipação de tutela devem ser sempre fundadas na análise da presença dos requisitos legais previstos no artigo 273 do CPC 14.

\section{Resultados e discussão}

Foram analisados 611 recursos de agravos de instrumento visando à modificação de decisões de 1a Instância que concederam ou negaram a tutela antecipada pelo consumidor contra operadoras de plano ou seguro de saúde, no período de janeiro de 2003 a setembro de 2004 (primeiro período de estudo) e 409, no período de setembro de 2004 a agosto de 2005 (segundo período de estudo).

O Estado de São Paulo contribuiu com o maior número de decisões em ambos os momentos estudados ( $n=511$ ou $83,6 \%$ e $n=352$ ou $86,1 \%$ ), respectivamente.

Não foi possível diferenciar, por meio da leitura dos acórdãos, quando se tratava de contratos firmados antes ou depois da vigência da $L e i$ $n^{o}$. 9.656/98 (contratos antigos e novos).

\section{Titularidade das ações}

Em ambos os períodos, dentre as 611 e 409 ações com pedidos de tutela antecipada julgadas, apenas duas eram coletivas $(0,33 \%$ e $0,49 \%$, respectivamente). Algumas hipóteses poderiam explicar essa diferença entre a quantidade de ações individuais e coletivas.

O enfoque da pesquisa é o primeiro aspecto a ser considerado, ou seja, decisões em pedidos de tutela antecipada. Como se trata de um instrumento jurídico voltado para as situações de urgência, a busca da Justiça tende a ocorrer no limite da necessidade do usuário de plano de saúde, como diante de uma negativa de cobertura específica para o seu caso concreto, ou da impossibilidade de pagar um aumento ilegal, ou ainda na iminência de ter seu contrato rescindido etc.

Nessas situações, o consumidor se vale de um advogado para cuidar do seu problema específico, uma vez que a propositura de ações por associações não é tão conhecida pela população. Além disso, há um reduzido número de organizações que atuam judicialmente no Brasil.

Outro aspecto que poderia justificar o número de ações judiciais coletivas é o fato de que uma ação individual pode ser uma medida mais célere do que apresentar uma representação ao Ministério Público ou reclamar aos PROCONs (Programa de Orientação e Proteção ao Consumidor) e às associações e aguardar as providências. No entanto, uma única ação coletiva pode beneficiar muitos consumidores de uma só vez, além de trazer impactos políticos significativos.

Nesse sentido, o desenvolvimento, a estruturação e o fortalecimento das associações de consumidores e da sociedade civil organizada são fundamentais, a fim de permitir o ajuizamento 
de ações de cunho coletivo para contestar a legalidade de práticas e/ou cláusulas contratuais abusivas, bem como ocupar espaços legítimos para a discussão do tema, além da Justiça.

\section{Temas avaliados}

Pode-se verificar, através da Figura 2, que, no primeiro período estudado, os temas mais incidentes foram: cobertura ( $\mathrm{n}=340$ ou $55,6 \%$ ), benefício legal - permanência no plano coletivo $(n=94 \mathrm{ou}$ $15,4 \%)$ e rescisão unilateral do contrato $(n=63$ ou 10,3\%). Juntos, esses temas corresponderam a $81 \%$ do total de decisões mais recorrentes na Justiça. Em relação ao segundo momento estudado, os temas mais recorrentes foram: cobertura ( $\mathrm{n}=$ 189 ou $46,2 \%$ ) e reajuste ( $n=121$ ou $29,6 \%$ ).

Comparando os resultados obtidos nos dois períodos, verificou-se que a ocorrência de pedidos de tutela antecipada relacionados ao tema cobertura reduziu de $55,6 \%$ para $46,2 \%$, enquanto os temas benefício legal - permanência no plano coletivo e rescisão unilateral do contrato apresentaram redução de 8,6 e 4,4 pontos percentuais, respectivamente (Figura 2).

O tema carência apresentou aumento de $2,1 \%(n=13)$ para $6,4 \%(n=26)$ em relação ao período anterior, enquanto o tema reajuste so- freu acréscimo ainda mais expressivo, passando de $3,4 \%(n=21)$ para $29,6 \%(n=121)$ do total das análises realizadas (Figura 2).

No tocante ao tema cobertura, verificou-se que as principais negações no primeiro período referiram-se a: coberturas diversas $(\mathrm{n}=126$ ou $37,1 \%$ ), próteses e outros materiais ( $n=48$ ou $14,1 \%$ ), obesidade mórbida ( $\mathrm{n}=38$ ou $11,2 \%$ ) e tratamento para câncer ( $\mathrm{n}=37 \mathrm{ou} 10,9 \%)$. Os temas relacionados à cobertura mais recorrentes no segundo momento do estudo foram: coberturas diversas ( $\mathrm{n}=55$ ou $29,1 \%$ ) e próteses e outros materiais ( $n=38$ ou 20,1\%) (Figura 3 ).

Os tipos de cobertura que apresentaram alterações mais significativas em comparação ao período anteriormente analisado foram: cobertura diversa (de $37,1 \%$ para $29,1 \%$ ), prótese (de $14,1 \%$ para $20,1 \%)$, tratamento/hospital não credenciado (de 3,8\% para $11,6 \%$ ) e urgência e emergência (de $4,1 \%$ para $2,1 \%$ ) (Figura 3 ).

Como exemplos de casos tratados no item coberturas diversas, pode-se citar: medicamentos, limitação de dias de internação e partos.

\section{Réu}

No que concerne aos planos e seguros de saúde que motivaram um maior número de pedidos

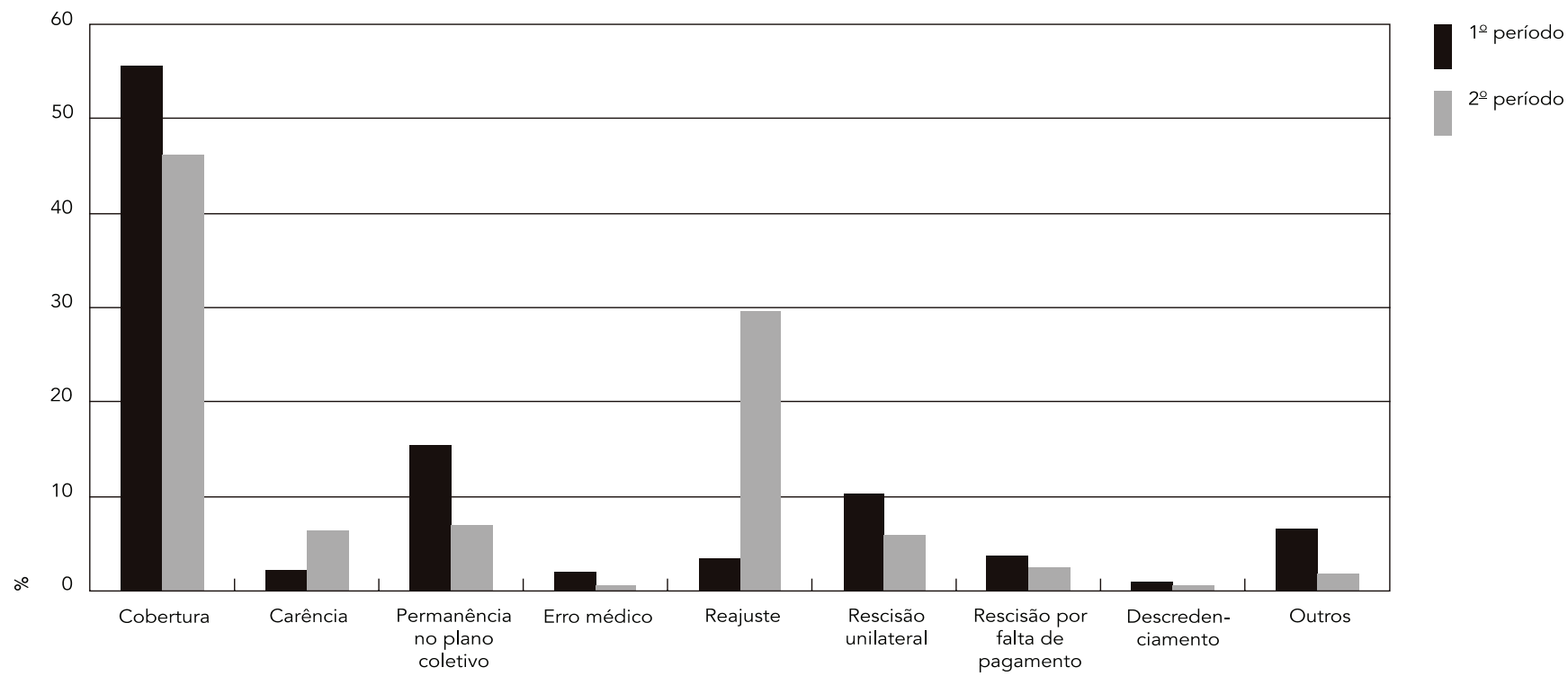




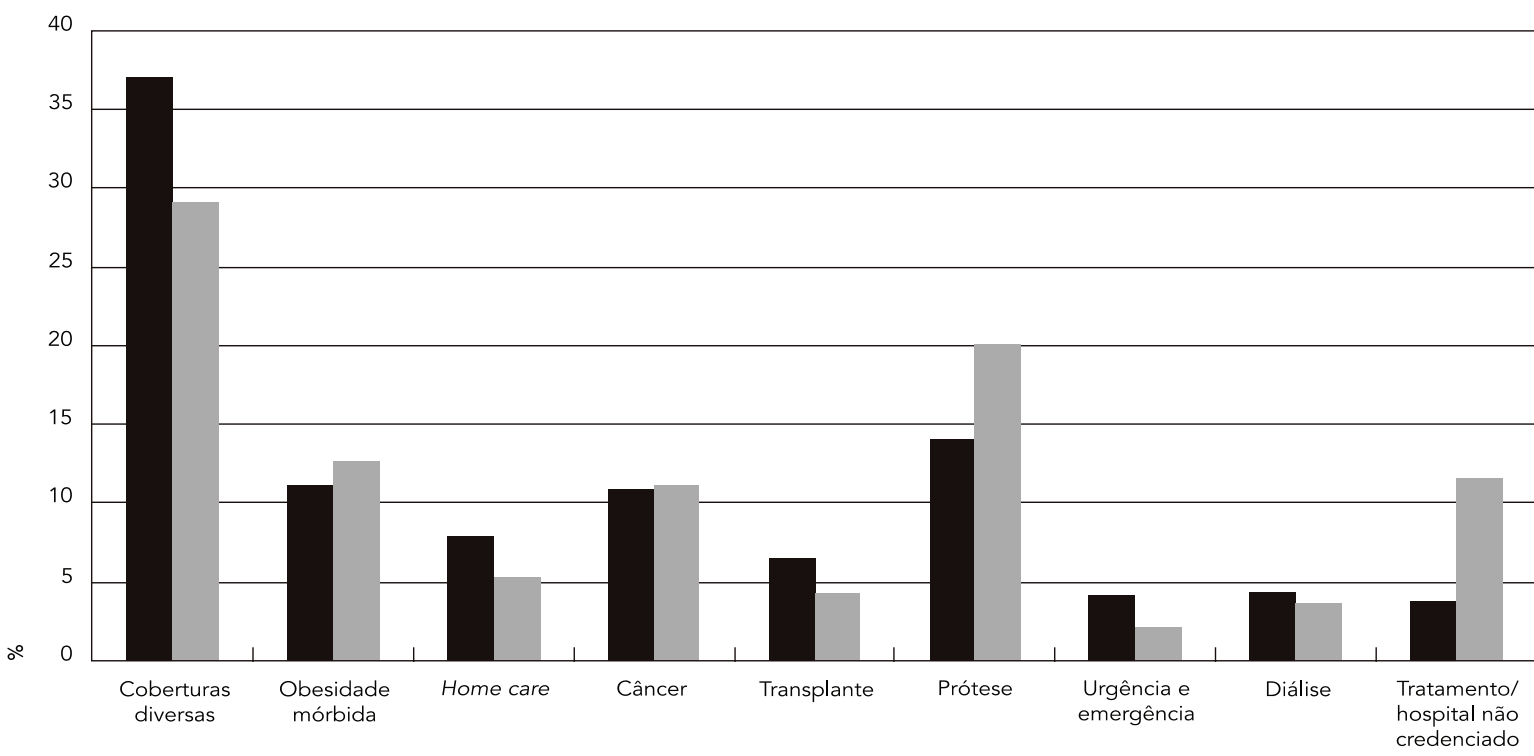

de tutela antecipada por parte dos consumidores, no primeiro período de análise, as operadoras Sul América, Unimed, Bradesco Saúde, Amil e Interclínicas corresponderam a 60\% (n = 368) das decisões; enquanto, no segundo período estudado, $70 \%(\mathrm{n}=286)$ dos pedidos foram motivados pelas operadoras Sul América, Bradesco Saúde, Unimed, Amil e Porto Seguro Saúde, considerando ambos os estados.

\section{Posicionamento da Justiça}

Quanto ao percentual de decisões que concederam a tutela antecipada, verificou-se que $80,7 \%$ ( $\mathrm{n}=493$ ) das decisões da 1a Instância e $72,8 \%$ ( $\mathrm{n}=445$ ) das decisões da 2ạ Instância foram favoráveis aos consumidores dos planos ou seguros de saúde no primeiro período de análise. No segundo período, tais percentuais foram de $79,7 \%(n=326)$ e de $78,2 \%(n=320)$, respectivamente. Nota-se que a 1a Instância foi mais favorável aos consumidores em ambos os períodos, no entanto, a diferença entre os percentuais de decisões favoráveis na 1a e 2ạ Instâncias foi menor no segundo período estudado.

A Figura 4 compara as porcentagens de decisões de 1ạ e 2ạ Instâncias favoráveis aos consumidores de planos ou seguros de saúde, de acordo com o tema analisado, nos dois períodos de análise.

No primeiro período, todos os temas apresentaram menos decisões favoráveis na $2^{\mathrm{a}}$ Instância, com exceção do tema reajuste, que aumentou de $52,4 \%(n=11)$ no primeiro período para $76,2 \%$ ( $\mathrm{n}=16$ ) no segundo. Ao comparar as duas instâncias, observou-se que os temas carência, erro médico e descredenciamento demonstraram reduções de $23,1 \%$, $50 \%$ e $60 \%$, respectivamente, nas porcentagens de decisões favoráveis. Enquanto isso, no segundo período, as diferenças percentuais relacionadas à concessão da tutela antecipada na 1a e 2a Instâncias foram menos significativas (Figura 4).

Avaliando, de forma discriminada, os itens considerados no tema cobertura quanto ao deferimento da tutela antecipada, no primeiro período, a 1ạ Instância foi favorável aos consumidores em $73,2 \%(n=249)$ dos casos, enquanto a 2a Instância o foi em $66,5 \%$ dos casos $(n=226)$. No segundo período, tais percentuais foram de 79,9\% $(n=151)$ e $79,4 \%(n=150)$, respectivamente.

A Figura 5 exibe as porcentagens de decisões de 1a e 2a Instâncias favoráveis aos consumidores de planos ou seguros de saúde, de acordo com os tipos de cobertura analisados, nos dois períodos de análise. 
Figura 4

Percentuais de decisões favoráveis na 1ạ e 2a Instâncias, em ambos os períodos estudados, de acordo com os temas analisados.

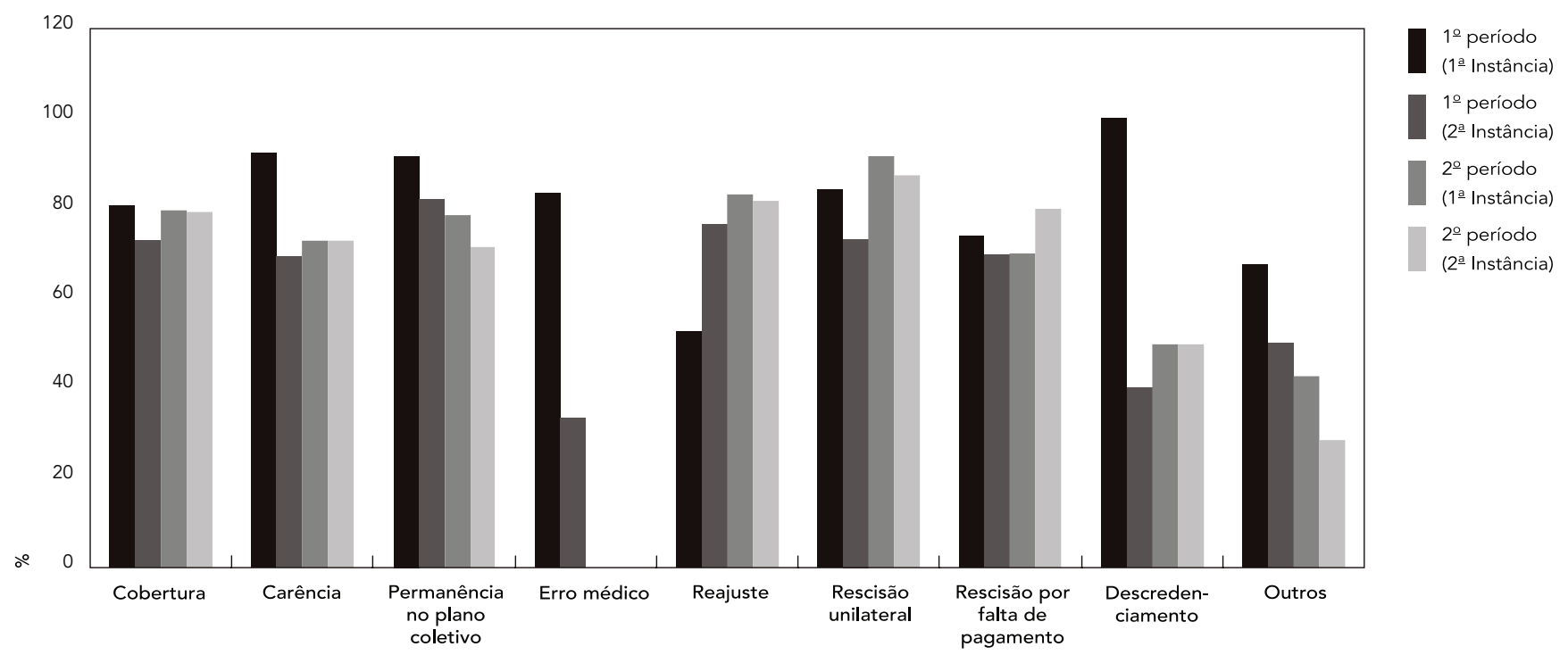

Figura 5

Percentuais de decisões favoráveis na 1ạ e 2ạ Instâncias, em ambos os períodos estudados, de acordo com os tipos de cobertura analisados.

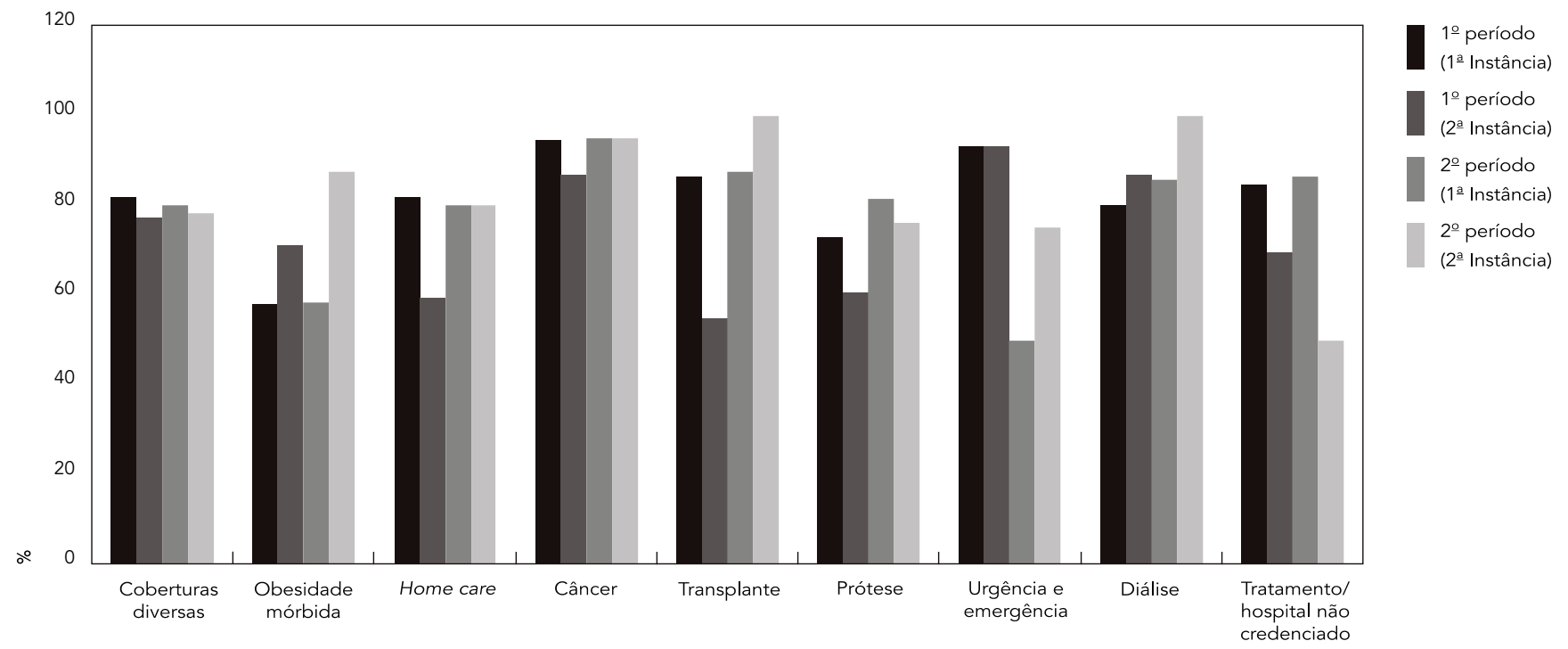




\section{Fundamentações}

Quanto às fundamentações utilizadas pelos desembargadores para justificarem a concessão ou não da tutela antecipada, o CPC foi o mais freqüentemente citado, aparecendo em $66,8 \%$ das decisões $(n=408)$ no primeiro período e em $88,3 \%$ ( $n=361$ ) no segundo período de análise (Tabela 1).

No segundo período, o item "outras fundamentações” também foi expressivo ( $\mathrm{n}=255 \mathrm{ou}$ $62,3)$, o que significa que os magistrados citaram referências bibliográficas, decisões julgadas anteriormente etc., ou seja, utilizaram outros recursos para fundamentar seus julgamentos (Tabela 1).

A Lei $n^{o}$.9.656/98, o CDC e a Constituição Federal de 1988 foram citados em menos de 50\% das decisões em ambos os períodos. No entanto, no segundo período de estudo, tais dispositivos legais foram mais citados, em comparação com o primeiro.

O pequeno percentual de decisões com citação da Lei $n^{o}$. 9.656/98 pode estar relacionado ao fato de muitos processos envolverem planos antigos. No entanto, conforme mencionado anteriormente, não foi possível diferenciar quando se tratava de contratos firmados antes ou depois da vigência dessa lei.

É importante ressaltar que, ao apreciar o pedido de antecipação de tutela, o juiz pode não adentrar no mérito da questão, mas apenas verificar se estão presentes os requisitos legais descritos anteriormente. Portanto, as decisões que compõem o universo pesquisado constituem respostas rápidas da Justiça aos beneficiários do sistema privado de assistência à saúde, não sendo, necessariamente, análises aprofundadas sobre o mérito das ações.

Marques relata qual deve ser o papel dos juízes quanto às demandas envolvendo relações de consumo. A jurista chama a atenção para a necessidade de se levar em consideração a função social do contrato na sua interpretação 18 (p. 227-8):

“Assim, também, a vontade das partes não é mais a única fonte de interpretação que possuem os juízes para interpretar um instrumento contratual. A evolução doutrinária do direito dos contratos já pleiteava uma interpretação teológica do contrato, um respeito maior pelos interesses sociais envolvidos, pelas expectativas legítimas das partes, especialmente das partes que só tiveram a liberdade de aderir ou não aos termos pré-elaborados.

As leis, aqui chamadas de leis intervencionistas, autorizam o Poder Judiciário a um controle mais efetivo da justiça contratual e ao exercício de uma interpretação mais teleológica, onde os
Tabela 1

Fundamentações utilizadas pelos magistrados da 2a Instância em suas decisões, em ambos os períodos de análise.

\begin{tabular}{lcc}
\hline Fundamentação & 10 período & 2o período \\
\hline Código de Defesa do Consumidor & 11,1 & 31,3 \\
Lei no. $9.656 / 98$ & 18,5 & 28,9 \\
Constituição Federal & 1,0 & 18,8 \\
Código de Processo Civil * & 66,8 & 88,3 \\
Outras & - & 62,4 \\
\hline
\end{tabular}

* No 1o período, o valor 66,8\% refere-se às fundamentações do Código de Processo Civil e outras.

valores da lei tomam o primeiro plano e delimitam o espaço para o poder da vontade. O juiz ao interpretar o contrato não será um simples servidor da vontade das partes será, ao contrário, um servidor do interesse geral. Ele terá em vista tanto o mandamento da lei e a vontade manifestada, quanto os efeitos sociais do contrato e os interesses das partes protegidos pelo direito em sua concepção social".

Esse papel vem sendo efetivamente desempenhado na prática, como demonstra a maioria das decisões analisadas, visto que alguns argumentos utilizados pelos julgadores para conceder ou manter os pedidos de tutela antecipada são baseados no direito à vida e à saúde e também no reconhecimento da abusividade das cláusulas contratuais que limitam ou excluem tratamento essencial à saúde do usuário. Verificou-se que muitas decisões basearam-se no CPC e não adentraram a questão do mérito.

A jurista citada anteriormente entende que a jurisprudência benéfica ao usuário de planos e seguros de saúde vem se firmando 18 (p. 393-4):

“Contratos de seguro, planos de saúde, planos funerários e previdência privada-Os contratos de seguro foram responsáveis por uma grande evolução jurisprudencial no sentido de conscientizar-se da necessidade de um direito dos contratos mais social, mais comprometido com a eqüidade, boafé e menos influenciado pelo dogma da autonomia da vontade.

As linhas de interpretação asseguradas pela jurisprudência brasileira aos consumidores em matéria de seguros são um bom exemplo da implementação de uma tutela especial para aquele contratante em posição mais vulnerável na relação contratual, antes e depois da entrada em vigor do CDC".

Apesar da consolidação da jurisprudência nesse sentido, em alguns casos, manifesta-se um 
entendimento mais conservador. A interpretação, nesses casos, pautou-se pela estrita observância das regras contratuais, sem considerar a função social do contrato e a boa-fé que deve reger as relações de consumo.

\section{Conclusões}

Por intermédio da presente pesquisa, pôde-se ter a noção do grau de responsabilidade do Poder Judiciário quando se trata da problemática envolvendo planos e seguros privados de saúde, uma vez que esse se tornou o espaço de discussão e reivindicação dos consumidores. Embora a regulação dos planos privados de saúde no Brasil tenha trazido grandes avanços, resultado da mobilização da sociedade civil, dos esforços governamentais e do trabalho do Poder Legislativo, a atuação do Estado no setor ainda apresenta lacunas 12 , visto que várias ações judiciais continuam tramitando na Justiça para a garantia de direitos.

No que se refere aos contratos antigos, foram garantidos alguns direitos da nova regulamentação, como: a proibição de limites de consultas e suspensão de internação, inclusive em UTI; proibição de rompimento unilateral para os contratos individuais; e controle dos reajustes dos contratos individuais. Apesar disso, cabe destacar que esses contratos apresentam várias restrições de cobertura assistencial em relação aos contratos que estão sob a égide da Lei $n^{o}$. 9.656/98.

O tema da adaptação de contratos antigos, por sua vez, gerou dificuldades na regulação do mercado, tendo em vista as dificuldades encontradas para conciliar o interesse dos consumidores e das operadoras. Os consumidores tinham interesse em obter as novas coberturas e garantias, no entanto, não estavam dispostos a pagar os preços estabelecidos pelas empresas de pla- nos de saúde 19. Dessa forma, os beneficiários de planos de saúde mantiveram o direito de permanecer com o plano antigo por tempo indeterminado e o de exigir a adaptação para um novo contrato, a qualquer tempo.

Segundo informações divulgadas pela ANS, os percentuais de beneficiários em planos antigos em 2003 16, 2004 20, 200521 e 200622 eram de $64,1 \% ; 47,5 \%$; $38,5 \%$; e $35,2 \%$, respectivamente.

Apesar de não ter sido possível diferenciar as lides envolvendo contratos regidos ou não pela Lei $n^{\circ}$. 9.656/98, sabe-se que o fato de a regulamentação não abranger os contratos antigos fez com que vários consumidores continuassem à mercê de cláusulas abusivas e baseadas em interesses econômicos, o que, certamente, chega ao Judiciário na forma de ações judiciais.

De acordo com Scheffer ${ }^{23}$, as futuras disputas entre os atores sociais na saúde suplementar serão relacionadas, entre outros fatores, à adaptação dos planos antigos, ao controle social do setor suplementar e à divulgação de dados epidemiológicos, econômicos e financeiros ao governo e à sociedade.

Nesse sentido, é de extrema relevância a atuação dos órgãos de Sistema Nacional de Defesa do Consumidor - coordenado pelo Departamento de Proteção e Defesa do Consumidor e composta pelos PROCONs estaduais, do Distrito Federal e municipais -, e das associações civis de defesa do consumidor, a fim de ensejar a participação social na construção da política voltada à assistência privada à saúde. Além disso, cabe destacar o importante papel da ANS no sentido de aumentar e aprimorar as informações divulgadas às operadoras de planos de saúde, aos prestadores de serviços, ao governo e à sociedade, assim como de preencher as lacunas ainda não solucionadas pela regulação, através da formulação de diretrizes norteadas pela concepção de que a saúde é um bem de relevância pública. 


\section{Resumo}

A grande quantidade de reclamações dos consumidores de planos e seguros privados de saúde se tornou freqüente no setor suplementar, com reflexos sobre o Poder Judiciário. Essa problemática fez surgir a necessidade de regulação desse mercado privado, que se iniciou em 1998, por meio da Lei no. 9.656. Um dos desafios que a Agência Nacional de Saúde Suplementar (ANS) enfrenta é a resistência das operadoras perante a legislação, além do fato de ainda existirem contratos não regidos pela referida lei. O objetivo do estudo foi analisar recursos de decisões judiciais que concederam ou não o pedido liminar da antecipação da tutela solicitado pelo consumidor de plano de saúde, julgados nos Tribunais de Justiça do Rio de Janeiro e de São Paulo. Os principais dados pesquisados foram: Tribunal que proferiu a decisão; réu; tema debatido; posicionamento de $1 \underline{a}$ e de $2 \underline{a}$ Instâncias e fundamentação jurídica. Verifica-se que o Poder Judiciário continua sendo um importante espaço de reivindicação dos consumidores de planos de saúde. O papel da ANS é importante para preencher algumas lacunas que ainda não foram solucionadas pela regulação do setor.

Planos de Pré-Pagamento em Saúde; Regulamentação Governamental; Poder Judiciário; Políticas Públicas

\section{Colaboradores}

D. C. Alves realizou as análises dos acórdãos e elaborou a parte escrita do artigo. L. Bahia foi responsável pela revisão crítica do artigo. A. F. Barroso contribuiu durante a análise dos acórdãos e no que se refere às questões jurídicas.

\section{Referências}

1. Travassos C, Viacava F, Fernandes C, Almeida CS. Desigualdades geográficas e sociais na utilização de serviços de saúde no Brasil. Ciênc Saúde Coletiva 2000; 5:133-49.

2. Souza RG, Bodstein RCA. Inovações na intermediação entre os setores público e privado na assistência à saúde. Ciênc Saúde Coletiva 2002; 7:481-92.

3. Médici AC. A medicina de grupo no Brasil. Brasília: Organização Pan-americana da Saúde; 1991. (Série: Desenvolvimento de Políticas Sociais, 1).

4. Scheffer M, Bahia L. Planos e seguros privados de saúde no Brasil: lacunas e perspectivas da regulamentação. In: Heimann LS, Ibanhes LC, Barboza $\mathrm{R}$, organizadores. O público e o privado na saúde. São Paulo: Editora Hucitec; 2005. p. 127-68.

5. Ocké-Reis CO, Andreazzi MFS. O mercado de planos de saúde no Brasil: uma criação do Estado? Revista de Economia Contemporânea 2006; 10:157-85.
6. Carvalho EB, Cecílio LCO. A regulamentação do setor de saúde suplementar no Brasil: a reconstrução de uma história de disputas. Cad Saúde Pública 2007 ; 23:2167-77.

7. Brasil. Lei no. 9.656, de 3 de junho de 1998. Dispõe sobre os planos privados de assistência à saúde. Diário Oficial da União 1998; 4 jun.

8. Brasil. Lei no. 9.961, de 29 de janeiro de 2000. Cria a Agência Nacional de Saúde Suplementar - ANS e dá outras providências. Diário Oficial da União 2000; 29 jan.

9. Bahia L. Planos privados de saúde: luzes e sombras no debate setorial dos anos 90. Ciênc Saúde Coletiva 2001; 6:329-39.

10. Agência Nacional de Saúde Suplementar. Evolução e desafios da regulação do setor de saúde suplementar. Rio de Janeiro: Agência Nacional de Saúde Suplementar; 2003. (Série ANS, 4). 
11. Almeida C. O mercado privado de serviços de saúde no Brasil: panorama atual e tendências da assistência médica suplementar. Brasília: Instituto de Pesquisa Econômica Aplicada; 1998.

12. Conselho Nacional de Saúde. Aporte de recursos públicos para planos privados de saúde. Comissão de Saúde Suplementar. Brasília: Conselho Nacional de Saúde; 2005.

13. Brasil. Lei $n^{\circ}$. 5.869, de 11 de janeiro de 1973 . Institui o Código de Processo Civil. Diário Oficial da União 1973; 17 jan.

14. Brasil. Lei no. 8.952, de 13 de dezembro de 1994. Altera dispositivos do Código de Processo Civil sobre o processo de conhecimento e o processo cautelar. Diário Oficial da União 1994; 14 dez.

15. Fux L. Tutela de urgência e plano de saúde. Rio de Janeiro: Espaço Jurídico; 2000.

16. Agência Nacional de Saúde Suplementar. Dados do setor. Rio de Janeiro: Agência Nacional de Saúde Suplementar; 2005.

17. Brasil. Lei no. 8.078, de 11 de setembro de 1990. Dispõe sobre a proteção do consumidor e dá outras providências. Diário Oficial da União 1990; 12 set.

18. Marques CL. Contratos no Código de Defesa do Consumidor: o novo regime das relações contratuais. São Paulo: Revista dos Tribunais; 2002.
19. Lima CRM, Oliveira RMS. Adaptação de contratos antigos entre operadoras privadas e beneficiários de planos de assistência à saúde. http://www. ans.gov.br/portal/upload/biblioteca/TT_OS_04_ CLima_AdaptacaoContratosAntigos.pdf (acessado em 02/Abr/2008)

20. Montone J. Evolução e desafios da regulação do setor de saúde suplementar. http://www.ans.gov. br/portal/upload/forum_saude/forum_bibliogra fias/Apres\%20Januario\%20Forum\%20-\%20vers\% C3\%АЗо\%20impressa.pdf.

21. Agência Nacional de Saúde Suplementar. ANS informação 2006. http://www.ans.gov.br/portal/ upload/informacoesss/DadosSetorl_27042006.pdf (acessado em 02/Abr/2008).

22. Agência Nacional de Saúde Suplementar. Caderno de informação da saúde suplementar: beneficiários, operadoras e planos. Rio de Janeiro: Agência Nacional de Saúde Suplementar; 2006.

23. Scheffer M. Propostas de aprimoramento da regulamentação dos planos de saúde. In: Simpósio Regulamentação dos Planos de Saúde. Brasília: Conselho Nacional da Saúde, Ministério da Saúde; 2001. p. 185-8.

Recebido em 25/Out/2007

Versão final reapresentada em 18/Jun/2008

Aprovado em 08/Jul/2008 